\title{
OFFSHORE WIND FARM MACRO AND MICRO SITING PROTOCOL APPLICATION TO RHODE ISLAND
}

\author{
Annette Grilli ${ }^{1}$, Malcolm Spaulding ${ }^{1}$, Christopher O’Reilly' ${ }^{1}$ and Gopu Potty ${ }^{1}$
}

Since 2008, the Rhode Island (RI) Coastal Resources Management Council has been leading the development of an Ocean Special Area Management Plan (Ocean SAMP), in partnership with the University of Rhode Island, resulting in an extensive multidisciplinary analysis of the Rhode Island offshore environment and its suitability to site offshore wind farms. As part of SAMP, a comprehensive macro-siting optimization tool: the Wind Farm Siting Index (WIFSI), integrating technical, societal, and ecological constraints, was developed within the conceptual framework of ecosystem services. WIFSI uses multivariate statistical analyses (principal component and $k$-means cluster analyses) to define homogeneous regions, which integrate and balance ecological and societal constraints as part of a Cost/Benefit tool. More recently, a Wind Farm micro-Siting Optimization Tool was developed (WIFSO), which uses a genetic algorithm to derive the optimal layout of a wind farm sited within one of the macro-siting selected regions. In this work, we present an overview of the current state of development of the integrated macro- and micro- siting tools.

Keywords: offshore wind farm; sitng optimization; genetic algorithm; cluster analysis; WIFSI; WIFSO

\section{BACKGROUND}

With the fast growth of offshore renewable energy permit requests filed with the Federal Energy Regulatory Commission (FERC), the marine spatial planning approach in the US has been progressing toward a truly sustainable approach for offshore energy conversion devices (OECD) deployment.

While it is standard to assess the viability of an offshore project using standard Cost/Benefit analyses, which balances the cost associated with the project over its lifetime, and the revenues extracted from the resource, it is important to also consider the ecological and societal impacts of the development. The complex permitting process and the intense involvement of stakeholders requires an approach, which balances the economics of the OECD with the technical, as well as societal and ecological constraints. An inclusive approach has become the new paradigm in OECD siting protocols.

Siting protocols generally identify exclusionary areas and areas of mitigation (Spaulding et al, 2010). Exclusionary areas exclude any OECD deployment, while areas of mitigation would, theoretically, welcome an OECD deployment, when the conflicts of use are minimal and the benefit of exploiting the energy resource is significant. In order to prioritize areas of mitigation, quantitative approaches based on objective optimization schemes have been developed.

Cost/Benefit approaches have been developed to optimize the siting of offshore wind farms (Elkinton et al., 2005). Standard costs, besides the structural cost, are primarily the foundation cost (function of water depth and geological environment), and the power cable cost (function of the distance between turbines, and between the farm and the main grid connection point). Cost should ideally be estimated over the fife-cycle of the plant, including maintenance and decommissioning costs (El-Thaljia and Liyanage, 2011). The benefit is proportional to the extractable power. Such a model can be combined with a GIS approach of societal and ecological constraints. Once the optimal areas are identified at the regional scale (macro-siting), the layout of the wind farm can be optimized at the scale of the farm (micro-siting). The Danish Technical University (DTU) has developed a state of the art turbine layout optimization scheme combining aerodynamics and technical constraints, resulting in a sophisticated micro-siting tool, TOPFARM (Rethore et al., 2010). TOPFARM provides several wake model options corresponding to increasing levels of sophistication in modeling wake processes.

The marine spatial planning approach to siting has adopted the traditional econometric concept of ecosystem services valuation (Costenza et al, 1987; Barbier et al, 2009) to develop an ecosystem services framework relevant to marine spatial planning (Mcleod and Leslie, 2009), and to develop

\footnotetext{
${ }^{1}$ Department of Ocean Engineering, University of Rhode Island, South Ferry Road, Narragansett, RI, 02882, US
} 
rigorous quantitative marine spatial planning tools (Tallis et al., 2010). However, the integration of an ecosystem services conceptual framework with marine spatial planning tools in the context of OECD siting is not frequently used and no systematic protocol combining those concepts, tools, and OECD aspects, has been established in the US. The Canadians have demonstrated a very rigorous siting approach at a national scale, based on ecosystem services (Williams and Campbell, 2012) In the US, however, rigorous efforts to quantify ecosystem services and integrate them in rigorous siting protocols are currently in development (White et al, 2012; Grilli et al, 2012).

In Rhode Island, since 2008, the Coastal Resources Management Council (CRMC) has been leading an Ocean Special Area Management Plan (Ocean SAMP) activity, in partnership with the University of Rhode Island, resulting in an extensive multidisciplinary analysis of the Rhode Island offshore environment and its suitability for siting an offshore wind farm (SAMP, 2010). At the conclusion of the study, two areas were identified as suitable for wind farm deployment. The Renewable Energy Zone (REZ) in Rhode Island State waters, South East of Block Island (BI) and the Area of Mutual Interest (AMI) between Rhode Island and Massachusetts, in Federal waters (Figure 1). As part of the SAMP project, a standard siting optimization approach was first developed based on a simple siting index defined as the ratio of cost of the extraction system to available wind resource. This approach provides a convenient macro-siting tool which can be used within a marine spatial planning context to address ecological and societal constraints (Spaulding et al., 2010). The multiple GIS layers required in this approach and the absence of theoretical support to optimize the resulting zoning, led to an expansion of our initial optimization approach into a more comprehensive macro-siting optimization tool, directly integrating societal and ecological constraints into the siting tool: the Wind Farm Siting Index (WIFSI) (Grilli et al, 2012). WIFSI was also developed within the ecosystem services framework and uses multivariate statistical analyses to integrate technical, ecological, and societal constraints into a macrositing tool. Macro siting is defined here as the procedure for locating those areas that are most suitable for ocean energy development. Our more recent work deals with the integration of a micro-siting optimization tool into the earlier macro-siting protocol, based on a genetic algorithm (GA), which provides an optimal wind farm layout inside an area identified as optimal at the macro-siting level. This Wind Farm Siting Optimization tool (WIFSO) is still in development and this paper presents its current status.

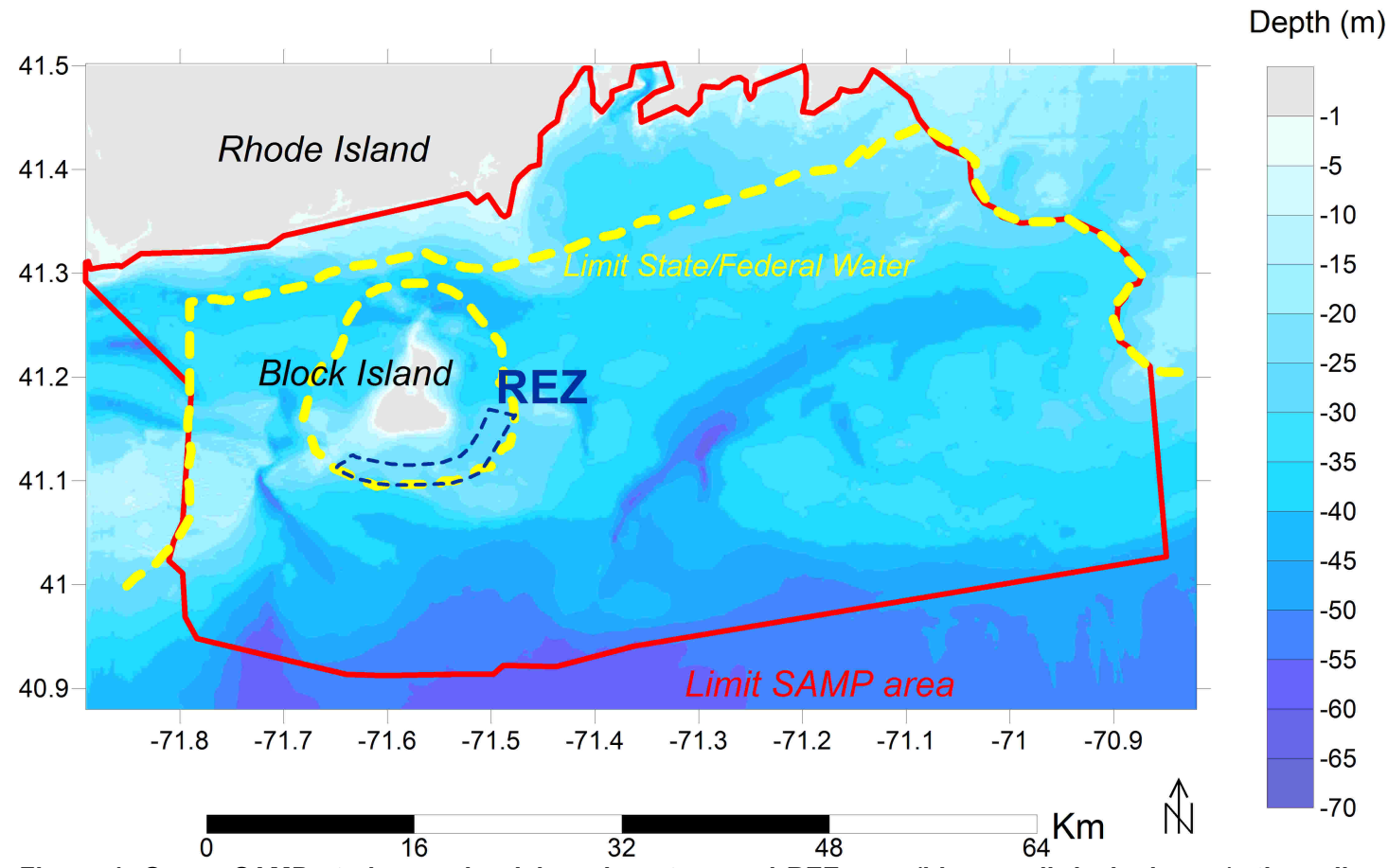

Figure 1. Ocean SAMP study area in plain red contour and REZ area (blue small dashed zone); the yellow dash line defines the limits of State Waters. 


\section{OFFSHORE WIND FARM MACRO-SITING APPROACH: THE CASE OF RHODE ISLAND OFFSHORE WATERS}

The macro-siting optimization performed as part of WIFSI is based on an optimization between cost of the extraction system (technical cost) and the resource, with the concept of cost expanded to include, in addition to the standard technical cost, the societal and ecological costs. The algorithm calculates and maps a non-dimensional WIFSI describing the suitability of a site for wind turbine deployment. The index is the ratio of "cost" to "resource". The resource term is proportional to the extractable power $(R)$, at a hypothetical turbine hub height, and the cost term is a weighted sum of nondimensional costs: technical (e.g. foundation and cable cost), societal (e.g., fisheries cost) and ecological (e.g., turbine impact on whales). Note that the costs of the extraction devices (e.g. wind turbines) are not included in the technical costs since they are assumed location independent. Weights are can be adjusted according to societal values or political choices. Despite a quest for rigor and objectivity, a "choice" stage is inherent to any valuation problem and is unavoidable even with the most rigorous and quantitative spatial planning approaches, once these involve intangible costs (Oumeraci et al. 2009; Burzel et al., 2010). The siting factors included in this macro-siting part of the analysis are presented in Table 1. Factors included in the micro-siting tool are also indicated. The development and validation of WIFSI are described in detail in Grilli et al. (2012) and summarized in the following. The methodology was applied to the SAMP study area, on a 200 by $200 \mathrm{~m}$ grid, requiring all data used to calculate the index be interpolated on that grid.

The WIFSI is a expressed as,

$$
W I F S I=\frac{W_{1} * T C+W_{2} * E C+W_{3} * F C}{R}
$$

with $T C$, the non-dimensional technical cost , $F C$ the non-dimensional fisheries and $E C$ the ecological costs, $R$ the wind resource term specified as the mean extractable power at the turbines site, and $W_{i}$, the weights attributed to each cost "type": technical, fishery, or ecosystem services. The sum of the weights is 1 . The index is non dimensional and is standardized on a 0 to 1 scale. The higher the value of the index the higher the combined cost relative to the power extracted. Each term is briefly described hereafter:

The technological constraint, $T C$, expresses the technical challenge associated with siting OECD at a particular site, and the delivery of the produced power from this site to the electric grid. $T C$ is defined as a function of two major components: (i) a structural component based on the technology type, $\tau C$; and (ii) an electrical component, $\Delta C$, representing the transmission grid

$$
T C=\frac{\tau C+\Delta C}{\max _{x y}(\tau C+\Delta C)}
$$

The electrical component $\Delta C$ is function of the cable cost, $c$, and therefore of the distance from the site to the closest electrical grid node and can be represented by

$$
\Delta C=\int_{D(x, y)} c d s
$$

with the cable cost, $c$, integrated along the cable path to shore (increment $d s$ ), covering a distance $D$ from the turbine location $(x, y)$. The structural cost, $\tau C$, is a function of the technology type and installation cost, For a bottom mounted structure (e.g., Monopile, Lattice Jacket), it is a function of water depth, $d$, and sediment type, $s$ (Papalexandrou, 2008; Sharma et al., 2010),

$$
\tau C=\tau C_{o,}+\tau C(d(x, y), s(x, y))
$$

with, the first term $\tau C_{0}$, a constant reflecting the base price for each specific technology, independent of the siting; and the second term a site dependent term, usually expressed as a polynomial function of the distance to shore and a discrete function of the sediment type. 
The wind resource term $R$ represents the extractable power defined as the usable power according to Hennessey's (1977) definition, adjusted to exclude the non-extractable power due to the Betz law limitations. Assuming that the wind is Weibull distributed, the extractable power $(R)$ is defined as the power available from the wind speed, $u$, Weibull probability distribution, $p(u)$, truncated for cut-in, $\left(u_{0}\right)$ cut-out, $\left(u_{2}\right)$, and rated speed limits, $\left(u_{1}\right)$ as,

$$
R=0.59\left[\int_{u_{0}}^{u_{1}} u p(u) d u+u_{1} \int_{u_{1}}^{u_{2}} p(u) d u\right]
$$

A two-parameter (shape and amplitude) Weibull distribution was found to accurately estimate the wind speed distribution in the SAMP area (Grilli and Spaulding, 2012).

The fisheries cost is based on the fisheries activity in a given area. It is defined as a linear combination of the fishing scores $(F S)$ for the three types of fishing activities: (i) commercial mobile gear; (ii) commercial fixed gear; and (iii) recreational (subscript $i=1,2,3$ ), normalized on a scale of 0 to 1 , with 1 indicating maximum impact (Smythe et al., 2010).

$$
F C=\frac{\sum_{i} F S_{i}}{\max \left(\sum F S_{i}\right)}
$$

The ecological cost is based on the sensitivity of the ecological communities to the wind farm impact. The methodology to estimate this ecological cost term at each grid point is detailed in Grilli et al. (2012). The method is based on an ecological typology of the area based on principal component and cluster analyses providing homogeneous marine landscape (oceanscape) regions associated with homogeneous ecological assemblages (Verfaillie et al., 2009). Each ecological region is defined by a particular assemblage, or group of species, each being more or less sensitive to wind turbines deployment. Each species is defined by values of a series of coefficients reflecting its sensitivity to underwater noise, electromagnetic fields, and turbidity. Species' sensitivity is independently defined for the construction and operation phases. An ecological services index $(E S I)$ is employed, which combines species abundance and sensitivity, and characterizes each ecological region, $k$. The Ecological Cost term $(E C)$ is a direct function of the ecological index

For each identified ecological region $k$, a score $S_{i}$ is assigned to each species $i$, based on its relative abundance in a particular cluster,compared to its distribution in the entire SAMP area. ESI is defined as a weighted root mean square (rms), i.e., the square root of the linear combination of each species' weighted score squared ( $S W S$ ), normalized on a scale of 0 to 1 , with 1 reflecting maximal impact,

$$
E S I_{c, o}=\operatorname{sign}\left(S W S_{c, o}\right) * \frac{\sqrt{\left|S W S_{C, O}\right|}}{N \sqrt{\max \left|\left(S_{i}^{2} * c_{i(c, o)}\right)\right|}}
$$

with,

$$
S W S_{C, O}=\sum_{i=1}^{N}\left(S_{i}^{2} * c_{i(c, o)}\right)
$$

and $N$ denoting the number of species in the regional population, and the subscripts $c$ and $o$ defining the construction and operation phase, respectively.

The global Ecological Cost index, combining construction and operation phases, is finally calculated for each ecological region $k$ as, 


$$
E C_{k}=\frac{\sum_{l=c, o} E S I_{l}}{\max _{k}\left(\sum_{l=c, o} E S I_{l}\right)}
$$

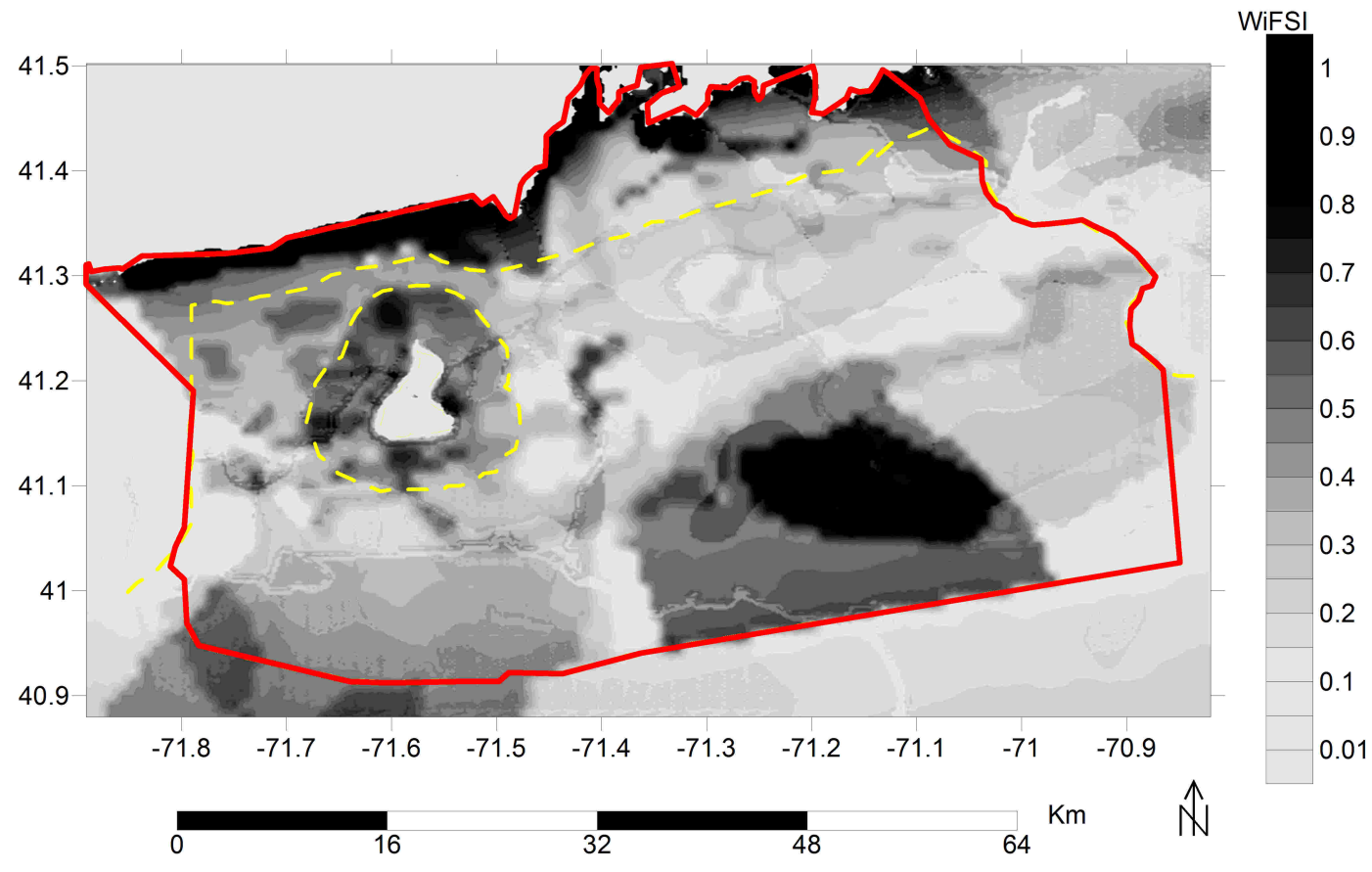

Figure 2: Application of the WIFSI siting protocol to the SAMP area. The most desirable areas for wind farm siting are denoted by lighter gray (low index values). The legend on the right gives the relationship between color and the index value. Note that exclusionary areas are not shown in this map. The yellow dashed line defines the limits of RI state waters in the Ocean SAMP area (red line).

The WIFSI tool allows the user to independently select any of the three constraints/costs or to combine them according to any weight combination. As an example, in Figure 2, we show the index in the SAMP area resulting from selecting an equal weight scheme for the three constraints. Dark (least gray) shaded areas have the highest (lowest) cost relative to power produced In this case areas with the highest index values are strongly correlated with intense fisheries activity.

The next part of the analysis focuses on the integration of the micro- and macro-siting constraints into an integrated micro-siting optimization tool, whose purpose is to optimize the wind farm layout design. The methodology is currently still development and is presently applied (in its initial stage of development) to the layout design of a wind demonstration site in the RI REZ area (Fig. 1), offshore of BI. The REZ area is the optimal area identified based on the lowest WIFSI values within state waters around BI (i.e., East and South East of BI) (Figure 2).

\section{OFFSHORE WIND FARM MICRO-SITING APPROACH: THE CASE OF BLOCK ISLAND}

Deep Water Wind Inc. (DWW) plans to install and commission six $6 \mathrm{MW}$ direct drive Siemens lattice jacket turbines in the REZ area, by 2014 (turbine characteristics: $110 \mathrm{~m}$ hub height; $154 \mathrm{~m}$ blade diameter). DWW and URI have been working cooperatively with the Department of Energy (DOE) National Renewable Energy Laboratory (NREL) and additional partners to develop a Southern New England Offshore Wind Demonstration Site (SNOWIDS), in the REZ area,'.

The micro-siting part of the analysis focuses on the inclusion of turbine wake effects into the resource term of the WIFSI, transforming the earlier macro-siting tool into a new integrated macro- and micrositing tool, the Wind Farm Siting Optimization tool (WIFSO). The wake from upwind turbines reduces 
the wind resources available to downwind turbines and thus affects the optimal location of individual turbines within a farm. In the present approach wake processes are modeled using the DTU (former RISOE) WAsP model. However, despite its simplicity this model was shown to perform as well as more sophisticated models, in particular, in terms of predicting wake shape and hub height velocity deficit (Barthelmie, 2006).

The proposed micro-siting optimization is achieved by implementing a genetic algorithm (GA). The application of the GA is in development and preliminary results applied to the siting of SNOWIDS are presented hereafter.

\begin{tabular}{|c|c|c|c|}
\hline \multicolumn{2}{|c|}{ RESOURCE AND CONSTRAINTS } & \multicolumn{2}{|c|}{ MITIGEABILITY OF SITING FACTORS } \\
\hline TECHNICAL COST & FACTORS & EXCLUSIONARY & MITIGEABLE \\
\hline \multirow[t]{3}{*}{ FOUNDATION COST } & DEPTH & & \multirow[t]{3}{*}{$\mathrm{X}$} \\
\hline & GEOLOGY & & \\
\hline & SEDIMENTOLOGY & & \\
\hline \multirow[t]{2}{*}{ CABLE COST } & DISTANCE TO COAST & & $\mathrm{X}$ \\
\hline & DISTANCE BETWEEN TURBINES & & $\begin{array}{ll}\text { INCLUDED } & \text { IN } \\
\text { MICROSITING } & \\
\text { (WIFSO) } & \end{array}$ \\
\hline \multicolumn{4}{|l|}{ RESOURCE } \\
\hline \multirow[t]{2}{*}{ WIND } & WIND POWER & & $\mathrm{X}$ \\
\hline & WAKE & & $\begin{array}{ll}\text { INCLUDED } & \text { IN } \\
\text { MICROSITING } & \\
\text { (WIFSO) } & \end{array}$ \\
\hline \multicolumn{4}{|l|}{$\begin{array}{l}\text { ECOSYSTEM } \\
\text { SERVICES }\end{array}$} \\
\hline $\begin{array}{l}\text { PROVISIONING } \\
\text { SERVICE }\end{array}$ & COMMERCIAL FISHERIES & & $\mathrm{X}$ \\
\hline \multirow{2}{*}{$\begin{array}{l}\text { CULTURAL } \\
\text { SERVICE }\end{array}$} & RECREATIONAL FISHERIES & & $\mathrm{X}$ \\
\hline & VISUAL IMPACT & $\mathrm{X}$ & \\
\hline \multirow{3}{*}{$\begin{array}{l}\text { REGULATING } \\
\text { SERVICE }\end{array}$} & BIODIVERSITY & & $\mathrm{x}$ \\
\hline & SPECIES RESILIENCE & & $\mathrm{X}$ \\
\hline & SPECIES RARITY/ENDANGERED & & $\mathrm{X}$ \\
\hline \multicolumn{4}{|l|}{$\begin{array}{l}\text { OTHER } \\
\text { EXCLUSIONARY } \\
\text { FACTORS }\end{array}$} \\
\hline WAVE CLIMATE & $\begin{array}{lcc}\text { EXTREME } & \text { WAVES } & \text { BREAKING } \\
\text { AREA }(50 \text { YEARS STORM- } 95 \% \mathrm{Cl})\end{array}$ & $\mathrm{X}$ & \\
\hline $\begin{array}{l}\text { FEDERAL AVIATION } \\
\text { ADMINISTRATION } \\
\text { REGULATION }\end{array}$ & & $\mathrm{X}$ & \\
\hline
\end{tabular}

Although the WIFSI analysis has identified REZ as an optimal siting area for a wind farm in BI state waters, the WFSI values are variable within this area (Fig. 2). Ideally, the wind turbines should be sited to avoid areas within REZ that have the highest WIFSI values, while minimizing the cable distance and avoiding areas in the wake of other turbines. In order to include the wake "effects" into the siting optimization an objective function $(O F)$, is included as a "modified" WIFSI.. The $O F$ differs from the WIFSI in its resource term $R$, which includes in addition to the mean wind speed, the mean speed deficit due to the wake "effect", $U_{w}$. The objective function is expressed as,

And the modified resource term as

$$
O F=\frac{T C+F C+E C}{R}
$$

$$
R=\left[\bar{U}-\overline{U_{w}}\right]^{3}
$$

Results are presented for one test case, for which only two wind directions were used: South-West (dominant South-West summer see breezes) and North-West (second dominant wind direction, strong North-West winds), with mean wind speed values set at 10 and $12 \mathrm{~m} / \mathrm{s}$ respectively. The GA 
optimization is run to optimize the layout of the 6 turbines on a $4 D$ grid spacing (with $D$, the turbine's blade diameter). The maximal footprint is defined by the state water limit on the East side and

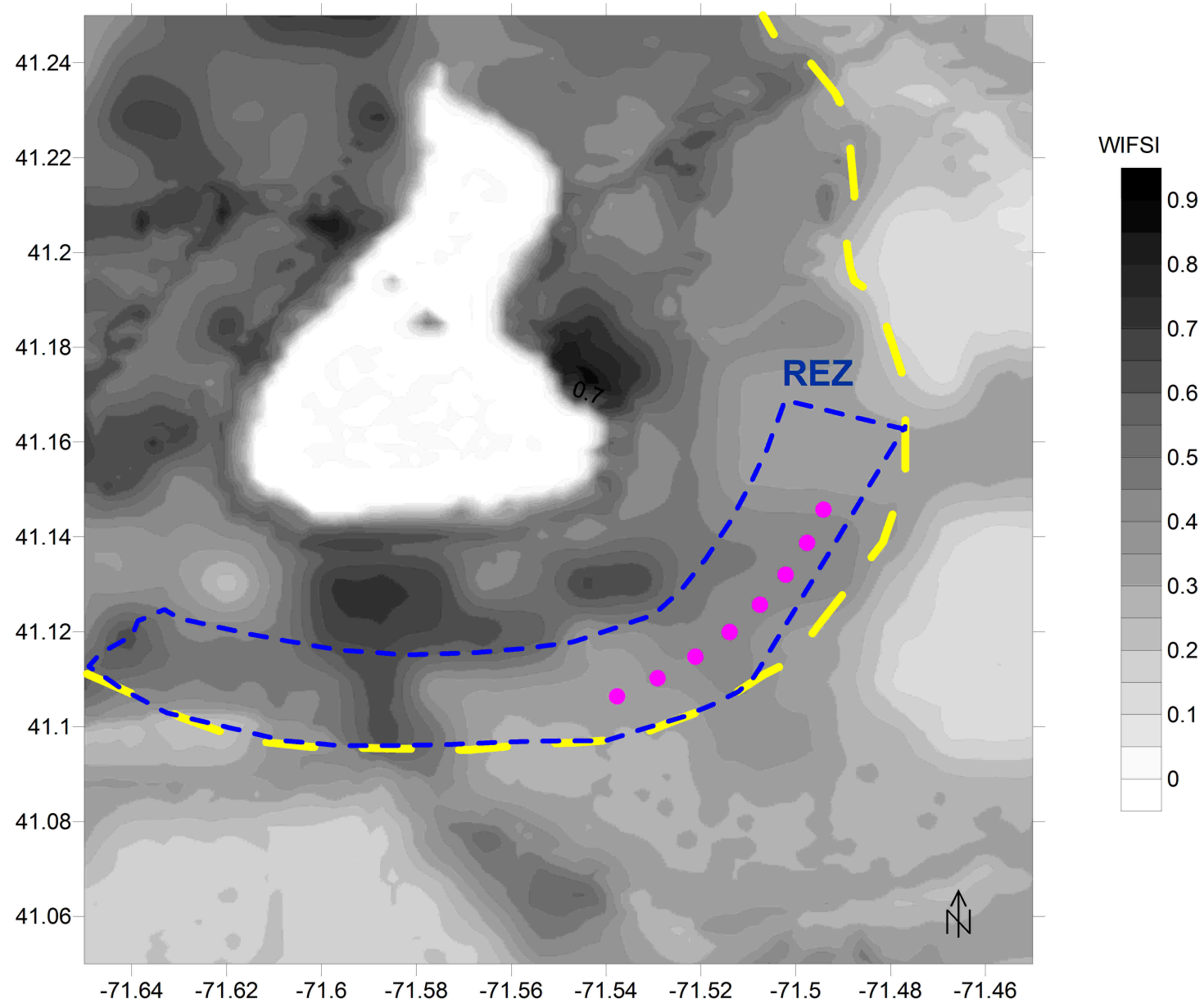

Figure 3: The small blue dashed line indicates the REZ area defined as a potential site for deploying wind turbines; dots symbols indicate the bore sites drilled by DWW. The large yellow dashed line denotes the limit of RI State waters.

by the developers bore holes limit on the North and South sides; visual impact from BI limit any development on the West side . Potential sites are defined by dots. The analysis results in optimal sites showed as blue dots in Fig. 4.

The WIFSO results in siting the turbines in areas described by the largest WIFSI values, but with the constraint to be aligned along a West-East axis, preventing the turbines to be in the lee of the other turbines when the dominant SW and NW winds are blowing (Fig. 4). The optimal layout is superimposed with the WIFSI index values.

\section{CONCLUSION}

The macro-siting tool, WIFSI, was demonstrated to be valuable as well as robust in the SAMP area. The current DWW proposed site for wind farm development correspond to optimal sites in terms of the WIFSI value. WIFSI constitutes a rigorous tool to help in siting offshore wind farms. It integrates technical, societal, and ecological constraints, while leaving room for stakeholders to introduce their input. The model provides adjustable weights at the ecosystem services level. For instance the weight associated to the fisheries cost term could be increased. It should be emphasized that ecological services are treated as intangible services, and cannot therefore be expressed in monetary terms. These 
are expressed instead as non-dimensional values, resulting in all costs and services being nondimensional.

The WIFSO is shown to be an efficient reliable micro-siting tool. More sophisticated wake models are planned to be included in the near future and used in combination with the GA. Additional WIFSO simulations will be performed in future work that will add more constraints on the farm footprint and use the full wind rose as wind input. Concentrating on analyzing the REZ area SE of BI, the objective will be able to provide a sensitivity analysis of the expected power output based on potentially "optimal" layouts. Note that the cable distance inside the farm and the resource term in the WIFSO are also being refined.

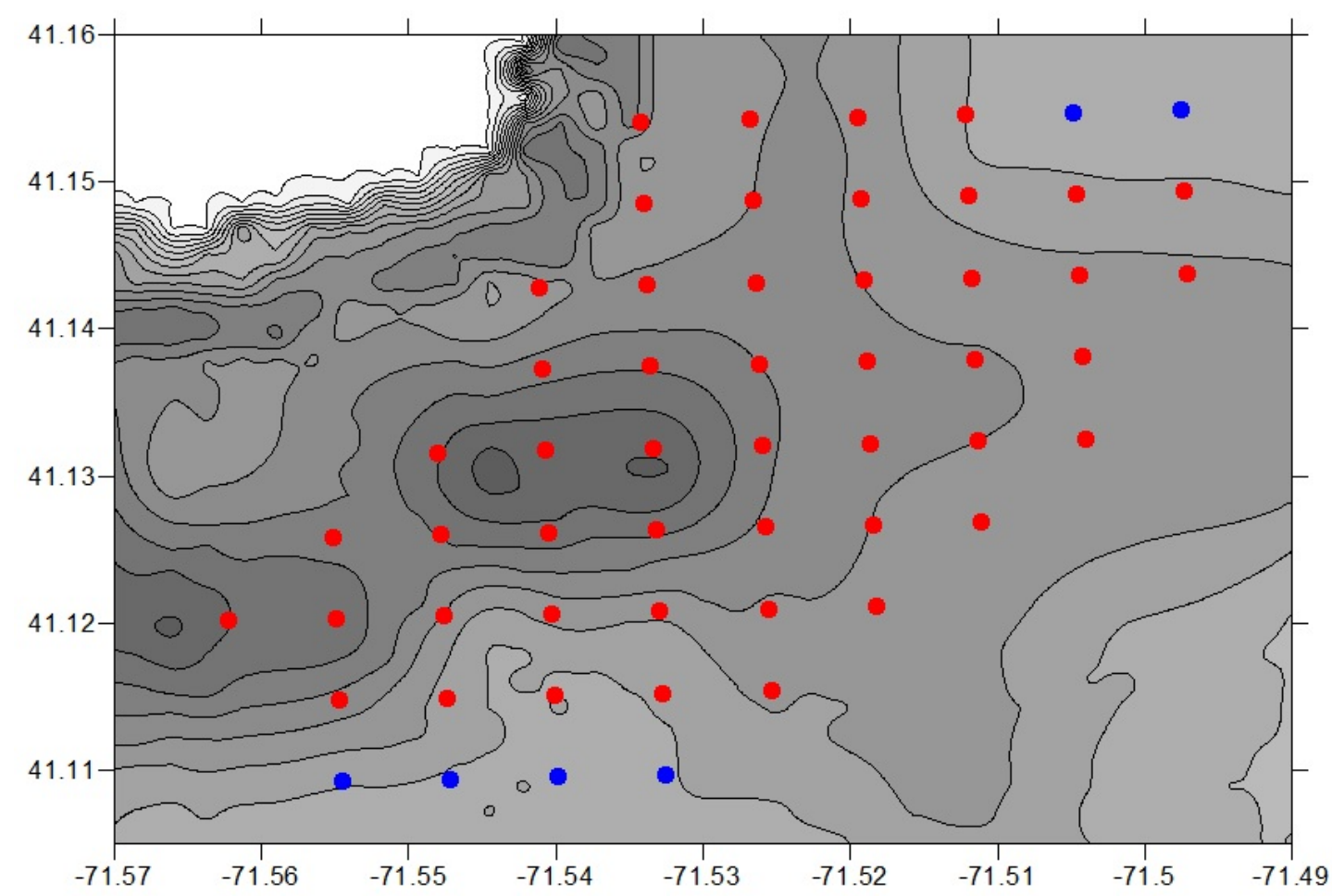

Figure 4: Example of possible optimal wind farm layout SE of $\mathrm{BI}$, based on a WIFSO, as a function of wake effects (using the GA) and WIFSI values (shown as a gray scale); blue dots denote optimal wind turbine sites.

\section{REFERENCES}

Burzel, A., Kortenhaus, A., Oumeraci, H., 2010. Ecosystem risk assessment in integrated risk analysis. Storm Surges Congress, Hamburg, Germany 13-17 September 2010.

Elkinton, C. N. , Manwell, J. F. and J. G. McGowan. 2005. Offshore Wind Farm Layout Optimization (Owflo) Project: An Introduction. Proceedings of The Offshore Wind Energy Conference, Copenhagen, 2005

Barbier, E.B, and Hanley, N. Pricing Nature: Cost-Benefit Analysis and Environmental Policy Making. Edward Elgard, London, 2009.

Barthelmie, R. J., Folkerts, L., Larsen, G.C., Rados, K., Pryor, S.C., Frandsen, S.T., Lange, B., Schepers, G., 2005. Comparison of Wake Model Simulations with Offshore Wind Turbine Wake Profiles Measured by Sodar, Journal of Atmospheric and Oceanic Technology. 23.

Costenza, R., d'Arge, R., Groot, R., Farber, S., Monica G., Hannon, B., Limburg, K., Naeem, S., O'Neill, R., Paruelo. J., Raskin. R.G., Paul Sutton, P., and van den Belt. M., 1987. The Value of the World's Ecosystem Services and Natural Capital. Nature. 387, 253-260. 
El-Thaljia and Liyanage, 2011. Design for Environmental Compatibility of Wind Power Systems: A Case Study on Offshore and Cold Climate from a Dependability Perspective". In Proc. 20th Intl. Offshore and Polar Engng. Conf. (Maui, Hawaii, USA, June 19-24)

Grilli, A.R., T. Lado Insua and M.L. Spaulding, 2012. A protocol to include ecosystem services constraints in a wind farm cost model. Journal of Environmental Engineering, in press.

Grilli, A.R. and Spaulding M.L., 2012. Estimation of mean offshore wind power resource in Southern New England coastal waters. Submitted to IJOPE.

Hennessey, J. P. 1977. "Some aspects of wind power statistics”, J. Appl. Meteor., 16, 119-128.

McLeod, K., and Leslie, H. 2009. Why ecosystem-based management? In: McLeod, K., and Leslie, H. (Eds.), Ecosystem-Based Management for the Oceans, Island Press, Washington, DC, 2009, pp. 3-6.

Oumeraci, H., Jensen J., Gönnert G., Pasche E., Kortenhaus A., Naulin M., Wahl T., Thumm S., Ujeyl G., Gershovich I., and A. Burzel. 2009. Flood risk analysis for a megacity: The German XtremRisK project, Proc. Conference on Road Map towards a Flood Resilient Urban Environment, Paris, France, 8 p.

Papalexandrou, M. 2008. Economic analysis of offshore wind farms, Master thesis. KTH School of Energy and Environmental Technology, Stockholm, Sweden.

Smythe T., Smith S., and Beutel D. 2010. Fisheries Activity Maps: Methods and Data Sources . Technical report for Rhode Island Ocean Special Area Management Plan, University of Rhode Island, Kingston, RI

Spaulding, M.L., Grilli, A.R., and Damon, C., and Fugate, G. 2010. Application of Technology Development Index and principal component analysis and cluster methods to ocean renewable energy facility siting, Marine Technology Society J., 44(1), 8-23.

Réthoré , P.E., Fuglsang, P., Larsen, G.C., Buhl, T., Larsen, T.J., Madse, H.A. 2011. TopFarm: Multifidelity Optimization of Offshore Wind Farm, Proceedings of the Twenty-first International Offshore and Polar Engineering Conference, Wind Energy Division, Risø DTU - National Laboratory for Sustainable Energy, Technical University of Denmark. Roskilde,

Sharma R., Hensel J., Baxter C., and Hu S-H J. 2010. "Development of a Technology Type Factor for Jacket Structures for Offshore Wind Turbines in Rhode Island", Technical Report for Rhode Island Ocean Special Area Management Plan, University of Rhode Island, Kingston, RI.

Tallis, H.T., Ricketts, T., Nelson, E, Ennaanay, D., Wolny, S, Olwero, N Vigerstol, K.,Pennington, D., Mendoza, G., Aukema, J., Foster, J., Forrest, J., Cameron, D, Lonsdorf, E.,Kennedy, C. 2010. InVEST 1.004 beta User's Guide, The Natural Capital Project, Stanford.

Verfaillie E., Degraer S., Schelfaut K., Willems W., Van Lancker V., 2009. “A protocol for classifying ecologically relevant marine zones, a statistical approach”. Estuarine, Coastal and Shelf Science. 83 -2 , 175-185.

White, C., Halpern, BS., Kappel, CV. 2012. "Ecosystem service tradeoff analysis reveals the value of marine spatial planning for multiple ocean uses", Published online before print March 5, 2012, doi: 10.1073/pnas.1114215109 PNAS March 20, 2012 vol. 109 no. 12 4696-4701.

Williams D. and Campbell D. 2012. Canada's Approach to Marine Spatial Planning - an ecosystem based approach. Oral Presentation at the International Marine Spatial Planning Symposium, Providence, Rhode Island, May 16, 2012. http://www.slideshare.net/riseagrant/williamscambell 